\section{Hotel-Based Rheumatology, and More}

\section{To the Editor:}

Reading the editorial by Drs. Pincus, Yazici, and Bergman in the August issue of The Journal ${ }^{1}$, I could completely agree with the content of the article, which is rarely the case. From many discussions, the last ones during the European League Against Rheumatism congress 2008 in Paris, I have learned that numerous — primarily practicing — rheumatologists, like me, share the authors' opinion. Examples often better illustrate controversial issues than many paragraphs. Therefore, I would like to recount a little event at the occasion of an industry sponsored symposium in the lovely city of Barcelona in 2003. An expert rheumatologist lectured on the treatment of "typical" patients with rheumatoid arthritis, advocating thresholds of disease activity scores as a must to achieve in case of high quality clinical care. My coworker, who was in charge of the outpatient clinic at that time, was sitting beside me and listening with keen interest. After a few minutes she asked me, "Why does this guy tell me that I'm treating my patients badly? He should visit us and sit at my desk. Then he'll learn what it means to negotiate treatment changes with a single patient." The speaker's primary field of interest was not daily rheumatology care, although he talked about that.

Pincus and colleagues argue that disease activity scores, such as the DAS $^{2}$, cannot constitute the exclusive basis of treatment decisions in daily routine. And of course, they are completely right ${ }^{3,4}$. However, more and more, the rheumatology community is confronted with the results of cohort studies applying those indexes as endpoints or decisive measures. These studies are presented as the ne plus ultra example of daily care ${ }^{5,6}$. Certainly, cohort studies are of great importance, if new compounds have to be examined. However, after having successfully proven a compound's efficacy and tolerability, those studies, all conducted under the rules of the intention-to-treat principle and applying last-observation-carried-forward (LOCF) statistics, are not capable of providing value for the daily management of individual patients, e.g., the question, Which drug for which patient? First and most important, no physician ever has the chance to treat cohorts in daily practice. Second, to really transfer the results of cohort trials into individual patient care, the respective patient's characteristics at least have to meet the $95 \%$ confidence interval of the study population, which is extremely unlikely, given the restrictive inclusion criteria of clinical trials. Third, in general we rarely see highly active patients included into such studies, as the likelihood of a response in those patients can be expected to be higher.

Two other aspects should be mentioned very briefly. Most of these addon cohort trials give predictable results, as a kind of self-fulfilling prophe$\mathrm{cy}^{6}$. And, has anyone ever considered treating a patient in daily routine as LOCF? This patient most likely will seek another rheumatologist for care. Attending many conferences and large congresses during recent years, one could gain the impression that most of the hotel-based rheumatologists indeed are convinced that individual patients must behave like the cohorts they usually report on. And this relates to another issue, the creation of recommendations. Many rheumatologists, including me, have participated in panels elaborating many such papers ${ }^{8,9}$. However, the number of recommendations attempted to be validated in daily practice, whether or not they really contribute to improved patient care, can probably be counted with the fingers. Expert recommendations, of course, could remarkably improve daily rheumatology care; but, if they are not disseminated, discussed, and widely accepted, they remain l'art pour l'art. Additionally, patients' perceptions, originally constituting an integrative part of evidence-based medicine, are usually deliberately neglected in this respect ${ }^{10}$.

The vast majority of rheumatologists are engaged in routine patient care. Indeed, it is a strange situation if somebody, having personally treated even $10 \%$ of the patients compared to the average rheumatologist in the audience, teaches patient care. On the contrary, practicing rheumatologists should demand research goals they regard as necessary to support and ease their daily work. But as long as these calls are not loud and frequent enough, the stage will be open for eloquent and elegant eminences.

In order to maintain our credibility and not to waste time and resources, we all should increase our efforts to enhance research reliability as well as improve the quality of meetings and conferences. Educational events primarily should be informative, provide opportunities for discussion, and boost exchange of knowledge and experiences. One crucial prerequisite are speakers independently presenting their views based on both evidence and their own experience. Another is clinical research based on the needs of the majority of rheumatologists.

BURKHARD F. LEEB, MD, Director 1st and 2nd Department of Medicine, Center for Rheumatology, Lower Austria; State Hospital Stockerau; Director, Karl Landsteiner-Institute for Clinical Rheumatology, A-2000 Stockerau, Landstrasse 18, Austria. E-mail: burkhard.leeb@ stockerau.lknoe

\section{REFERENCES}

1. Pincus T, Yazici Y, Bergman MJ. Hotel-based medicine. J Rheumatol 2008;35:1487-8.

2. Prevoo ML, van 't Hof MA, Kuper HH, et al. Modified disease activity scores that include twenty-eight-joint counts. Development and validation in a prospective longitudinal study of patients with rheumatoid arthritis. Arthritis Rheum 1995;38:44-8.

3. Leeb BF, Haindl PM, Maktari A, Nothnagl T, Rintelen B. DAS28 values differ considerably depending on patient's pain perception and sex. J Rheumatol 2007;34:2382-7.

4. Leeb BF, Andel I, Sautner J, Nothnagl T, Rintelen B. The DAS28 in rheumatoid arthritis and fibromyalgia patients. Rheumatology Oxford 2004;43:1504-7.

5. Breedveld FC, Weisman MH, Kavanaugh AF, et al. The PREMIER study: A multicenter, randomized, double-blind clinical trial of combination therapy with adalimumab plus methotrexate versus methotrexate alone or adalimumab alone in patients with early, aggressive rheumatoid arthritis who had not had previous methotrexate treatment. Arthritis Rheum 2006;54:26-37.

6. Emery P, Breedveld FC, Hall S, et al. Comparison of methotrexate monotherapy with a combination of methotrexate and etanercept in active, early, moderate to severe rheumatoid arthritis (COMET): a randomised, double-blind, parallel treatment trial. Lancet 2008;372:375-82. Epub 2008 Jul 16.

7. Sokka T, Pincus T. Eligibility of patients in routine care for major clinical trials of anti-tumor necrosis factor alpha agents in rheumatoid arthritis.Arthritis Rheum 2003;48:313-8.

8. Furst DE, Breedveld FC, Kalden JR, et al. Updated consensus statement on biological agents for the treatment of rheumatic diseases. Ann Rheum Dis 2006;65 Suppl:iii2-15.

9. Zhang W, Doherty M, Leeb BF, et al. EULAR evidence based recommendations for the diagnosis of hand osteoarthritis - report of a task force of the EULAR Standing Committee for International Clinical Studies Including Therapeutics (ESCISIT). Ann Rheum Dis 2008 Feb 4. [Epub ahead of print]

10. Hynes RB, Sacket Dl, Gray JMA, Guyett GH. Transferring evidence from research into practice. 1. The role of clinical care research evidence in clinical decisions. Evidence Based Medicine 1996;1:196-7.

J Rheumatol 2009;36:2; doi:10.3899/jrheum.080818 